\title{
Scaling the Daytime Urban Heat Island and Urban-Breeze Circulation
}

\author{
JULIA HidALGO \\ Environment Unit, LABEIN-Tecnalia, Derio, Spain \\ VALÉRY MASSON \\ GAME/CNRM, Météo-France, CNRS, Toulouse, France \\ LUIS GIMENO \\ EphysLab, Vigo University, Ourense, Spain
}

(Manuscript received 5 February 2009, in final form 17 November 2009)

\begin{abstract}
The urban-breeze circulation is a mesoscale response of the atmospheric flow that is related to horizontal variations in temperature associated, for dry conditions, with gradients in sensible heat flux densities. This local circulation is difficult to observe with a simple observational deployment, and the 3D numerical simulations needed to model it are very demanding in computer time. A theoretical approach scaling the daytime urban heat island and urban-breeze characteristics has been developed and provides a simple set of equations that depend on measurable parameters. Three-dimensional high-resolution numerical simulations, performed with the Nonhydrostatic Mesoscale (Meso-NH) atmospheric model, were used to generate a set of urban-breeze circulations forced by an idealized urban environment. The pertinent forcing parameters chosen were the size of the city, the height of the thermal inversion topping the mixed turbulent air layer, and the difference (urban - rural) of surface heat flux. Scaling laws are presented that describe the shape of the urban heat island and the horizontal and vertical wind intensity and profiles.
\end{abstract}

\section{Introduction}

The urban heat island (UHI) is defined as the excess of temperature frequently observed in a metropolitan area in comparison with the surrounding area. The UHI has a typical daily cycle (Oke 1982): it increases during the late afternoon and reaches its maximum during the night (5-8 K for a medium-sized European city), decreasing after dawn and generally reaching a minimum value during the morning hours, when it is possible to reach negative values. After that, it starts to increase again and, during daytime, the warmth accumulated can reach 1-2 K (Shea and Auer 1978; Yoshikado 1992; Hidalgo et al. 2008a). The urban-breeze circulation is a mesoscale response of the atmosphere to horizontal variations in temperature that are associated, for dry

Corresponding author address: Julia Hidalgo, Environment Unit, LABEIN-Tecnalia, C/Geldo - Parque Tecnológico de Bizkaia, Ed. 700, 48160, Spain.

E-mail: jhidalgo@labein.es conditions, with gradients in sensible heat flux densities. The UHI is then the source of the urban-breeze circulation. Because of the thermally induced horizontal pressure gradient, convergent motions toward the city core form at lower levels, with divergent motions forming above. As a result, the warmer air rises over the city and a local circulation begins, with colder air from the rural surroundings being drawn in over the city center (Fig. 1). The daytime urban breeze was documented by Wong and Dirks (1978) and Hidalgo et al. (2008a) using aircraft data from the field campaigns of the Metropolitan Meteorological Experiment (METROMEX) in St. Louis, Missouri, in 1974 (Changnon 1981) and the Canopy and Aerosol Particles Interactions in Toulouse Urban Layer (CAPITOUL) in Toulouse, France, in 2004-05 (Masson et al. 2008), respectively. The urban-breeze circulation has also been studied numerically using an atmospheric numerical model coupled with an urban surface energy balance (SEB) model. For example, simulations were carried out by Lemonsu and Masson (2002) over Paris, France, and by Hidalgo et al. (2008b) over Toulouse 


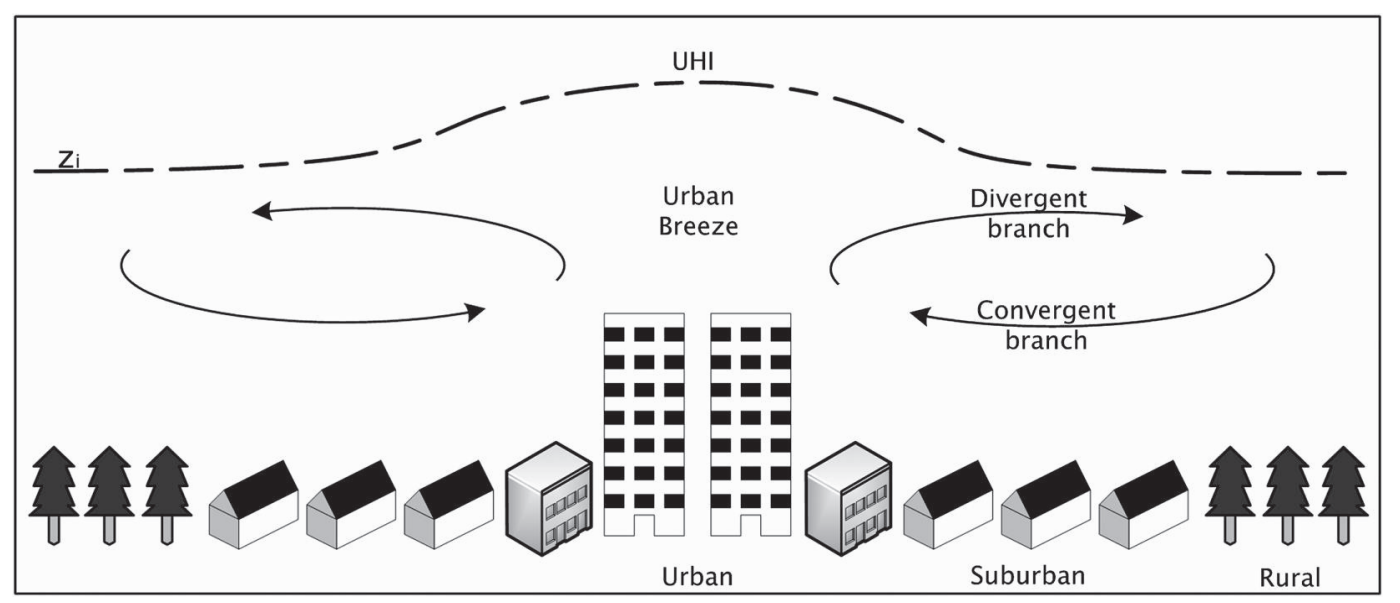

FIG. 1. Schematic vertical cross section of the urban boundary layer of height $z_{i}$ in the case of the urban-breeze circulation in a hinterland city.

using the mesoscale atmospheric Nonhydrostatic Mesoscale (Meso-NH) model (Lafore et al. 1998) with a Town Energy Balance urban scheme (Masson 2000). The latter study demonstrated the role of the surface energy balance in the development of low-level airflow convergence toward city centers.

This local circulation is difficult to observe with a simple observational deployment, and the 3D numerical simulations needed to model it are great consumers of computer time. A theoretical approach can fill this gap and provide a simple set of equations that describes the UHI and urban-breeze features.

Theoretical studies focusing on urban-breeze scaling generally fall into three categories: analytical, experimental, and nonlinear numerical modeling. Analytical studies are based on idealized solutions of the timedependent conservation equations, which employ various degrees of linearization. The analytical solution is complex, so approximations are used to simplify the governing equations. Analytical studies directed toward the UHI were developed in the 1970s and 1980s (Olfe and Lee 1971; Lin and Smith 1986; Lin 1987). Experimental data from laboratory studies using a water tank are described in Lu et al. (1997a,b) and Cenedese and Monti (2003). There currently are insufficient observational datasets of urban-breeze circulation to obtain the scaling laws as done by Steyn (1998) for sea-breeze circulation. Two-dimensional numerical calculations were used by Richardone and Brusasca (1989), Baik (1992), and Yoshikado (1992) and, more recently, by Baik and Chun (1997) and Baik et al. (2001).

Most of the studies cited here are centered essentially on nighttime under stable atmospheric conditions. Only two authors have studied day- and nighttime differences in urban-breeze circulation: Yoshikado (1992) and Cenedese and Monti (2003), who both used the Lu et al. (1997b) bulk convection model for daytime conditions. Both studies concentrated on the UHI interaction with the daytime sea breeze. To date, no study has focused in depth on daytime urban-breeze circulation in a hinterland city.

In previous studies, the heat flux at the surface and the turbulent thermal diffusion processes were not directly coupled. Instead, the thermal forcing was prescribed directly (Olfe and Lee 1971; Lin and Smith 1986; Baik et al. 2001). As indicated in numerous works by Baik (Baik 1992; Baik and Chun 1997; Baik et al. 2001), numerical models with detailed physics are more appropriate than models with a specified heating distribution. This approach was taken by Kurbatskii (2001) using a model with a prescribed heat flux at the surface to verify the scaling of Lu et al. (1997a) for the nocturnal UHI.

Porson et al. (2007) showed that mesoscale models having advanced parameterizations can be used to reproduce mesoscale circulations by means of scaling techniques. Idealized numerical simulations reduce the dependence of scaling laws on site-specific features, such as topographic influences, climatological urbanrural temperature gradients, surface layer heat flux regimes, and surface roughness. In the literature, no study uses 3D numerical simulations to examine the physical processes involved in daytime urban-breeze circulation. The aim of this paper is to investigate how external forcings control the speed and the vertical and horizontal length scales. In this study, 3D high-resolution numerical simulations, performed with the Meso-NH atmospheric model, were used to generate a set of urban-breeze circulations forced by an idealized urban environment. 


\section{Physics of the problem}

The scaling technique is a well-known approach used to describe turbulent flows. Its basic assumption is that, for some specific meteorological conditions, the structure of the lowest kilometers of the atmosphere (directly influenced by the earth's surface) can be described in terms of only a few characteristic governing parameters (Holtslag and Nieuwstadt 1986). Scaling laws for nocturnal UHI developed by Lu et al. (1997a,b) are analyzed to develop the focus of this paper, that is, comparing the differences between nocturnal and diurnal UHI scaling. The aim of this section is to provide a set of scaling laws for the UHI and urban-breeze circulation under daytime conditions.

\section{a. Current theory relating to the nocturnal UHI and the urban breeze}

In midlatitudes, during the night, a stable layer of air generally forms in rural areas because of surface cooling. Under calm wind conditions (i.e., conditions favorable to the formation of the UHI), there is no mixing of the air by wind shear and the nocturnal stable layer inversion is strong. This inversion is typically characterized by its potential ambient temperature gradient ( $\partial \theta / \partial z ;$ Fig. 2$)$ or, as an alternative, by the Brünt-Väisälä frequency:

$$
N=\left(\frac{g}{\theta} \frac{\partial \theta}{\partial z}\right)^{1 / 2} .
$$

This nocturnal inversion can reach a few hundred meters in height. Over a city, however, the SEB is modified and the air is heated by the surface. This reduces the cooling of the atmosphere but is not strong enough to prevent it. However, it is sufficient to maintain mixing with the air above by dry convection. This leads to the development of a neutral or slightly unstable turbulent layer above the city with a small capping inversion above (Fig. 2). Therefore, during the night, this ambient rural stability plays a key role in determining both the UHI intensity and the strength of circulation (Shreffler 1978, 1979; Vukovich and Dunn 1978; Richardone and Brusasca 1989).

Lu et al. (1997a) studied the UHI circulation in such a stratified environment by nondimensionalizing the governing equations of motion in an axisymmetric cylindrical coordinate system. The Coriolis force, internal heat generation, and radiation were ignored. Furthermore, the surface heat flux in the rural area was considered to be negligible (but its consequence over time, the strongly stratified nocturnal inversion, was considered).

Lu et al. [1997a, their Eq. (13)] showed that, under the stated (typically nocturnal) conditions, the UHI can be properly modeled by combining only three external (or forcing) parameters:

1) the characteristic diameter of the city: $D(\mathrm{~m})$,

2) the ambient thermal stratification, characterized by its Brunt-Väisälä frequency: $N\left(\mathrm{~s}^{-1}\right)$, and

3) the surface heat flux of the city: $H_{u}\left(\mathrm{~K} \mathrm{~m} \mathrm{~s}^{-1}\right){ }^{1}$

Using a scale model (water tank) and an analysis of the equations, the authors defined four scales ( $\mathrm{Lu}$ et al. 1997b):

1) $D$ as the length scale,

2) $U_{D}=\left(\beta D H_{u}\right)^{1 / 3}$ as the radial velocity scale, where $\beta=g \theta^{-1}$,

3) $U_{D} F_{r}$ as the vertical velocity scale, where $F_{r}=$ $U_{D} /(N D)$ (the Froude number), and

4) $U_{D} N \beta^{-1}$ as the temperature scale.

Note that, if one accepts the different symbols used here for nomenclature coherence, the second one $\left(U_{D}\right)$ is essentially Eq. (9) in $\mathrm{Lu}$ et al. (1997b), the third one $\left(U_{D} F_{r}\right)$ is their Eq. (6), and the fourth one $\left(U_{D} N \beta^{-1}\right)$ is their Eq. (8). Combining these scales allows scaling laws to be obtained for unknown properties of the flow, as $\mathrm{Lu}$ et al. defined for their tank experiment. The scaling law obtained for UHI intensity according to the defined scales is UHI $=1.61 U_{D} N g^{-1} \beta^{-1}$, which could be expressed as a function of governing variables as UHI $=$ $1.61 N\left(D H_{u}\right)^{1 / 3} \beta^{-2 / 3}$. The nondimensional structures of the UHI and of the flow velocities were also obtained by Lu et al. (1997a,b).

\section{b. Daytime UHI and urban breeze: Environment description}

During the day, the structure of the lower atmosphere is completely different from its structure at night. In the rural area, the heating of the surface by the sun in the morning produces a heat flux toward the air above that is sufficient, first, to destroy the nocturnal stable layer and, second, to mix the air (the so-called mixed layer in Fig. 2) by turbulence to a much higher altitude over the urban canopy $\left(z_{i}\right)$, where a capping temperature inversion occurs. This temperature inversion is linked not to the nocturnal stable layer (which is near the surface) but more to the previous day's capping inversion (which is still present above the nocturnal inversion, as shown

\footnotetext{
${ }^{1}$ Note that the surface heat flux can be retrieved directly from the corresponding surface heat flux in the SEB by $Q_{H}=\rho C_{p} H_{u}$ $\left(\mathrm{W} \mathrm{m}^{-2}\right.$ ) (where $\rho$ is the air density, typically $1.2 \mathrm{~kg} \mathrm{~m}^{-3}$ at low altitudes, and $C_{p}=1004 \mathrm{~J} \mathrm{~K}^{-1} \mathrm{~kg}^{-1}$, i.e., the heat capacity of air at constant pressure). Note also that the surface heat flux was expressed in watts per centimeter squared in Lu et al. (1997a) but that this has no impact on adimensional quantities.
} 

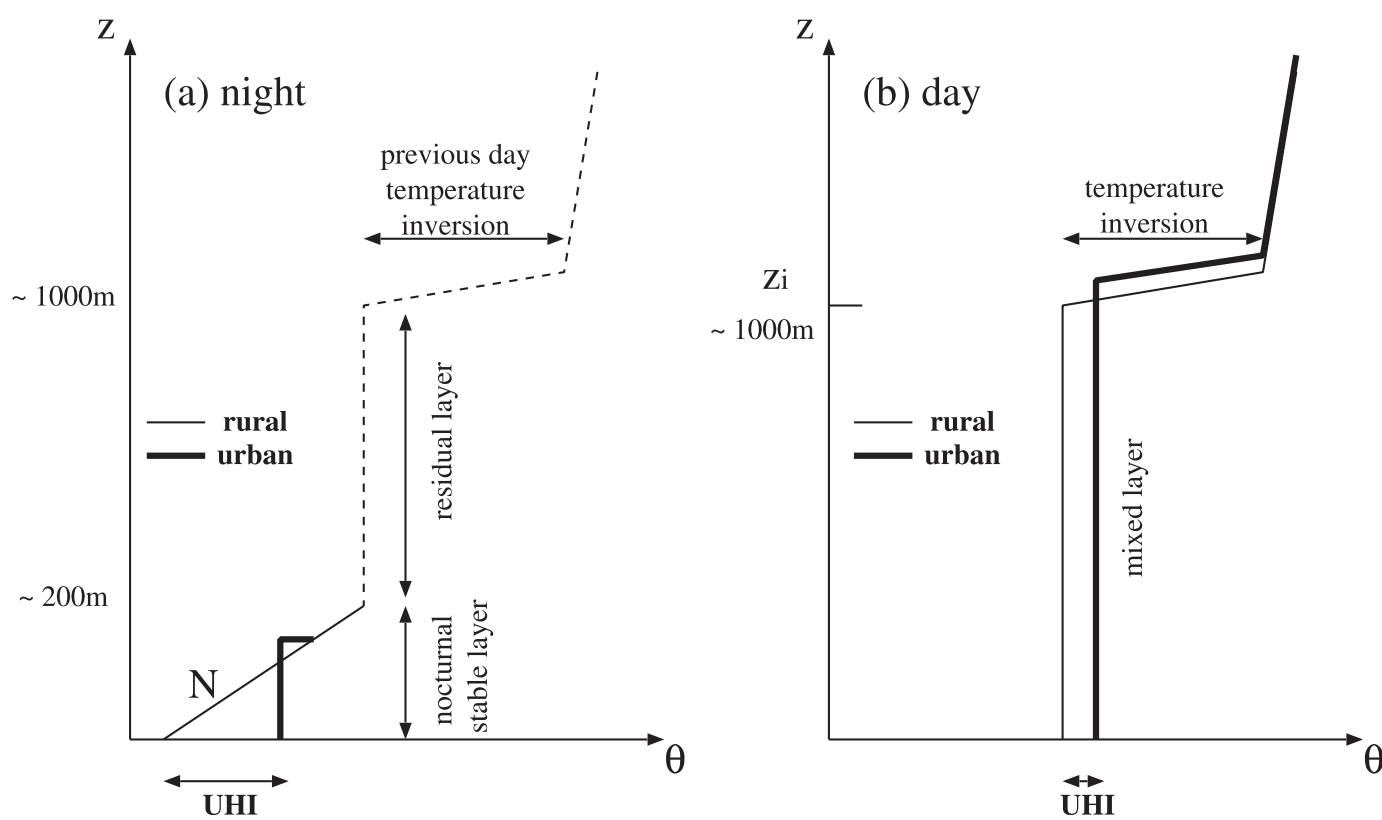

FIG. 2. Schematic representation of $\theta$ profiles associated with the UHI during the (a) night and (b) day. Thin lines are for rural profiles, and thick ones are for urban profiles. The dashed line in the night case represents the typical structure of the atmosphere above the nocturnal stable layer; $N$ represents the Brunt-Väisälä frequency.

by dashed lines in Fig. 2), the general meteorological situation, and the total heating of the air by the surface during the day. This inversion altitude $z_{i}$ typically varies between 500 (in winter) and $2000 \mathrm{~m}$ (during some hot days in summer).

The presence of a city will modify the SEB by heating the atmosphere above it. However, this alteration produces only a relatively minor modification of the vertical structure of the rural mixed layer temperature: the urban boundary layer will be a little warmer (the daytime UHI) and a little more turbulent and will extend slightly higher.

The urban breeze will therefore influence the atmosphere up to the capping temperature inversion at altitude $z_{i}$. Apart from this, there is no major effect on the stability. The rural mixed layer in which the urban breeze develops is unstable. The capping thermal inversion is very stable (generally more so than any nocturnal stable layer), and therefore its exact stability value is not significant in itself. The fact that it acts as a lid, blocking upward motions of air from the surface, is the more important point. The Brunt-Väisälä frequency, used by Lu et al. (1997a), is then no longer a useful parameter for describing the environment of the UHI and the urban breeze. It is replaced by the inversion height parameter $z_{i}$.

A further difference from the nocturnal case is that, during the day, the surface heat flux in the rural area can be significant. In the morning, at least, the surface heat flux is sufficient to build up the mixed layer, and, more often than not, it remains positive during the entire day. However, the rural heat flux is lower than the urban equivalent because the plants consume a large part of the solar energy available for latent heat. This difference in the heat flux between the city and the rural area is what causes the UHI and the urban-breeze circulation to occur during the day. In consequence, this parameter is highly relevant for this study. Hereinafter it is denoted as $\left(H_{u}-H_{r}\right)$.

\section{c. Daytime UHI and urban breeze: Scaling laws}

Once the forcing parameters of the problem have been identified, the general form of the scaling laws of each quantity of interest (i.e., the UHI or breeze intensity) can be deduced using similarity theory. This is based on the use of a nondimensional number obtained using the parameters of interest to the study and the pi theorem of Vaschy-Buckingham (Vaschy 1892; Buckingham 1914).

The pi theorem requires that all of the governing parameters (forcing, internal forces, and independent variables) that influence the UHI or the urban breeze be identified. As discussed in section $2 b$, the pertinent forcing parameters are 1 ) the diameter $D$ of the city (m), 2) the ambient capping inversion height $z_{i}(\mathrm{~m})$, and 3) the difference of surface heat flux between the city and the rural surroundings $\left[\left(H_{u}-H_{r}\right) ; \mathrm{K} \mathrm{m} \mathrm{s}^{-1}\right]$, which replace the $D, N$, and $H_{u}$, used by Lu et al. (1997a) for the nocturnal case. 
This study is limited to the case with no mean wind (it would be a forcing parameter in a more general case), and therefore this parameter is not taken into account. The main internal force is gravity. The heated air at the surface has a lower density than the surrounding air and so will move upward relative to the colder (and therefore denser) air above it. This feature could be represented by the gravitational constant $g$, but in atmospheric problems it is more common to use the buoyancy coefficient $\beta=$ $g \theta^{-1}$ (where the Boussinesq hypotheses are valid). For the urban breeze, given that short periods of time (an afternoon) will be considered, the Coriolis force (that would be characterized by its frequency $f$ ) will not be taken into account. Therefore, the only internal force parameter is the buoyancy $\beta\left(\mathrm{m} \mathrm{s}^{-2} \mathrm{~K}^{-1}\right)$.

Independent parameters (that will be used when characterizing the nondimensional shape of some characteristics of the urban breeze) are 1) distance $x$ from the center of the city (m) and 2) height $z$ above the ground (m).

From these six external parameters, scales can be determined for length $\left(D_{s}\right)$, speed $\left(W_{s}\right)$, and temperature $\left(\theta_{s}\right)$, and these can be used to describe the intensity of the associated urban-breeze characteristics. One nondimensional number $\left(z_{i} / D\right)$ will describe the relative influence of the city size on the capping inversion height. Two additional nondimensional numbers $\left(x / D\right.$ and $\left.z / z_{i}\right)$ will be used only if a spatial description of the phenomenon is required.

The three characteristic scales derived for length, velocity, and temperature are

$$
\begin{aligned}
D_{s} & =D, \\
W_{s} & =\left[\beta z_{i}\left(H_{u}-H_{r}\right)\right]^{1 / 3}, \text { and } \\
\theta_{s} & =\frac{H_{u}-H_{r}}{W_{s}}=\left(H_{u}-H_{r}\right)^{2 / 3}\left(\beta z_{i}\right)^{-1 / 3} .
\end{aligned}
$$

Scales for velocity and temperature are formally equivalent to those obtained by Lu et al. [1997b, their Eqs. (9) and (8), respectively]. Note that the velocity scale is, in form, comparable to the convective velocity scale $w_{*}$ (Deardorff 1970; Stull 1997), except that $w_{*}$ uses the surface heat flux whereas our velocity scale uses the difference in surface heat flux between the urban and rural areas because, as discussed in section $2 b$, this is what forces the UHI circulation.

The general form of the UHI and urban breeze can then be determined. The UHI intensity is UHI = $\theta_{s} f_{\mathrm{UHI}}\left(z_{i} / D\right)$. The horizontal shape of the UHI is given by $\operatorname{UHI}(x / D)=\theta_{s} f_{\mathrm{UHI}}\left(z_{i} / D, x / D\right)$. The vertical and radial intensities of the urban breeze are $W=W_{s} f_{w}\left(z_{i} / D\right)$, $U_{r}=W_{s} f_{u}\left(z_{i} / D\right)$, and so on.
The problem is that none of the functions $f_{x}$ in these general relations are known and they cannot be determined from the similarity theory alone. Analytical simplifications of the fluid dynamic equations, experiments, or numerical simulations must be used to estimate the final forms of these relationships. In this, a numerical approach is taken.

\section{Description and validation of numerical experiments}

A set of 40 numerical simulations was performed using the Meso-NH atmospheric model to simulate the dynamics of the atmosphere (Fig. 3). As shown in section $2 \mathrm{c}$, the difference between urban and rural surface turbulent sensible heat flux $\left(H_{u}-H_{r}\right)$, the capping inversion $z_{i}$, and the diameter $D$ of the city were considered as the external forcing parameters. A set of these three parameters was chosen and fixed for each of the 40 simulations. Overall, $z_{i}$ varied from 1000 to $2500 \mathrm{~m}$ over the canopy (with values taken every $500 \mathrm{~m}$ ), $D$ was equal to 10 or $20 \mathrm{~km}$, and the difference between urban and rural surface turbulent sensible heat flux varied from 100 to $300 \mathrm{~W} \mathrm{~m}^{-2}$ with steps every $50 \mathrm{~W} \mathrm{~m}^{-2}$ [i.e., $\left(H_{u}-H_{r}\right)$ from 0.083 to $0.248 \mathrm{~K} \mathrm{~m} \mathrm{~s}^{-1}$ every $0.041 \mathrm{~K} \mathrm{~m} \mathrm{~s}^{-1}$ ].

The simulation was performed with a horizontal grid resolution of $500 \mathrm{~m}$, which is sufficient to study the fluid motions and properties at the scale of the whole city. The effects of the perturbations created by the city in the mean flow typically have a horizontal extent that is 2-3 times the size of the city itself (Hidalgo et al. 2008b), and so the horizontal domain $(150 \mathrm{~km} \times 150 \mathrm{~km})$ was large enough to prevent interferences from the (cyclic) boundaries. The vertical coordinate was composed of 35 levels over a vertical domain of $5 \mathrm{~km}$. The first atmospheric level was located $12 \mathrm{~m}$ above the urban canopy. Eighteen levels were located in the first $1000 \mathrm{~m}$. No water vapor was considered, the focus being on the purely thermally induced circulation. The roughness length $z_{0}$ that was imposed was $z_{0 R}=0.1 \mathrm{~m}$ for rural surfaces and $z_{0 U}=1.0 \mathrm{~m}$ for urban surfaces. The subgrid turbulence was parameterized following the scheme of Cuxart et al. (2000) and the mixing length of Bougeault and Lacarrère (1989).

The meteorological context of the experiments was an idealized anticyclonic summer situation representative of southern France. The atmosphere was characterized by an idealized vertical profile representing a sunny summer day, with a mixed layer (Brunt-Väisälä frequency $N=0 \mathrm{~s}^{-1}$ ) of depth $z_{i}$ (see Fig. 2b). At the top of the mixed layer, the capping temperature inversion layer was $50 \mathrm{~m}$ high with a strong stability $\left(N=0.06 \mathrm{~s}^{-1}\right)$, allowing $z_{i}$ to be controlled for each simulation regardless 


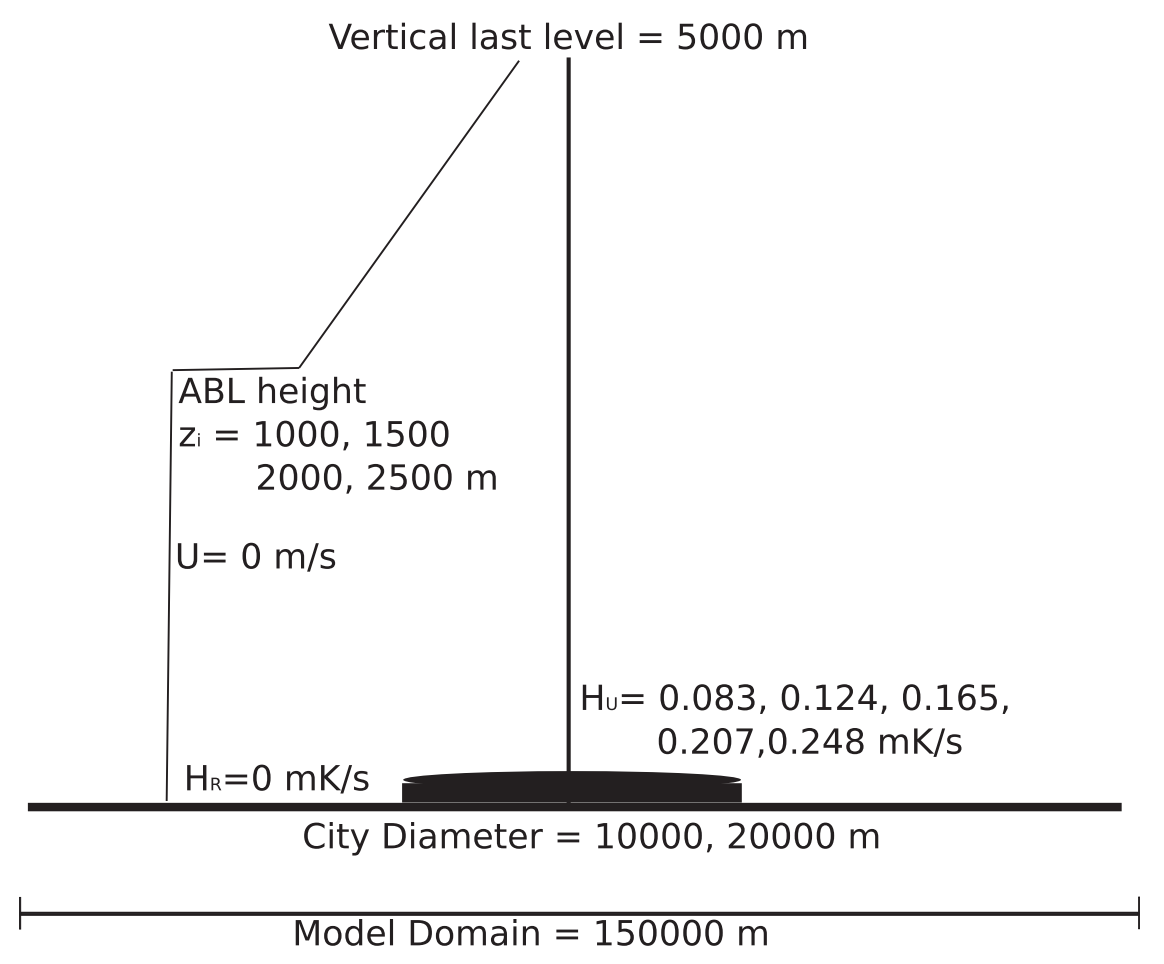

FIG. 3. Conceptual model and numerical simulation characteristics.

of the surface heat flux imposed. The atmosphere above was represented by a stability of $N=0.01 \mathrm{~s}^{-1}$. With these initial conditions set, a run of $3 \mathrm{~h}$ was performed for each of the 40 experiments. Results are displayed for the third hour of simulation, by which time a quasisteady state had been reached with a well-developed urban-breeze circulation.

The ability of the model to reproduce the urban breeze accurately in such an idealized context was verified by comparing the results obtained with the $D, z_{i}$, and $\left(H_{u}-H_{r}\right)$ parameters of the urban-breeze event observed during the intensive observation period (IOP5) in Toulouse on 4 July 2004 (Hidalgo et al. 2008a). Using the observed values for the forcing parameters $[D=$ $10000 \mathrm{~m}, z_{i}=2000 \mathrm{~m}$, and $\left(H_{u}-H_{r}\right)=0.165 \mathrm{~K} \mathrm{~m} \mathrm{~s}^{-1}$ $\left.\left(200 \mathrm{~W} \mathrm{~m}^{-2}\right)\right]$, the model produced a near-surface UHI (for the first atmospheric level at a height of $12 \mathrm{~m}$ ) of $1.5 \mathrm{~K}$ and a horizontal wind speed in the convergent branch of the urban breeze that reached a maximum of $2 \mathrm{~m} \mathrm{~s}^{-1}$, which compares well to the observations for a real city (Hidalgo et al. 2008a). The $2 \mathrm{~m} \mathrm{~s}^{-1}$ vertical wind speed in the upward motion of the urban breeze over the city is slightly larger than that obtained for the more realistic simulation of the 4 July case $\left(1.5 \mathrm{~m} \mathrm{~s}^{-1}\right.$; Hidalgo et al. 2008b). The simplifications made here in representing the physics of the UHI and urban breeze seem valid, allowing variations of the forcing parameters to define the scaling laws.

\section{Scaling the daytime urban-breeze circulation}

\section{a. Simulated UHI and urban-breeze features}

Figure 4 shows the profiles of the mean temperature distribution above the canopy [first atmospheric level $(12 \mathrm{~m})]$ as a function of the nondimensional length $x / D$ for the set of 40 simulations. The UHI intensity for different meteorological conditions (and therefore different mixed layer heights $z_{i}$ ) varies for different values of $\left(H_{u}-H_{r}\right)$. As the mixed layer height decreases, the volume of air available above the city for heating also decreases, and then the intensity of the UHI increases. For $z_{i}=2500 \mathrm{~m}$, the UHI at the city center ranges between 0.8 and $2 \mathrm{~K}$; for $z_{i}=1000 \mathrm{~m}$, it ranges between 1.3 and $3.3 \mathrm{~K}$. As expected, for a given mixed-layer height, the stronger the surface heat flux over the city is, the higher is the UHI. Multiplying the heat flux difference by 3 increases the UHI intensity by a factor of 2 .

For a given $z_{i}$ and urban-rural heat flux difference, doubling the size of the city does not have a significant impact on the surface UHI. This has already been pointed out by Atkinson (2002) who concluded that the size of urban areas had a minimal (but not null) effect on UHI intensity. Under daytime conditions, the reduced evaporation over cities [and hence the larger heat flux, associated with the higher $\left.\left(H_{u}-H_{r}\right)\right]$ is the most important factor. This is confirmed by the scaling laws below. 



FIG. 4. Horizontal profiles of surface temperature distribution as a function of the nondimensional length $x / D$. The black lines correspond to the simulation for $D=10 \mathrm{~km}$, and the gray lines correspond to the simulation for $D=20 \mathrm{~km}$. The center of the city is located at $x / D=0 ;$ the edge of the urban area lies at $x / D=0.5$.

The maximum radial velocity is reached over $0.2 \leq$ $x / D \leq 0.4$ (suburban area), and the maximum vertical velocity is over $0 \leq x / D \leq 0.2$ (city center). Figures 5 and 6 show the mean vertical profiles of radial velocity (averaged over $x / D=0.2-0.4$ ) and vertical velocity (averaged over $x / D=0-0.2$ ) as a function of the nondimensional height $z / z_{i}$. The radial (convergent) velocity is at a maximum at low levels $\left(0.05 z_{i}\right)$. The flow reversal height is around $0.6-0.7 z_{i}$. The vertical wind speed intensity decreases relative to the diameter of the city, whereas the absolute horizontal wind speed is not sensitive to it. Mass conservation then induces a smaller vertical motion for larger city areas. On the other hand, the increase of the vertical branch in the center of the urban breeze as a function of $z_{i}$ is simply caused by the additional buoyancy available. The higher the mixed layer is, the higher is the unstable layer inside it and the longer the air parcels can accelerate vertically. A larger $\left(H_{u}-H_{r}\right)$ also increases the buoyancy effect on the vertical velocity $W$ and slightly increases the horizontal wind convergence (at lower levels) and divergence (at higher levels) $\left(U_{r}\right)$.

\section{b. A new set of scaling laws}

The shape and intensity of the urban temperature anomaly, as well as the wind profiles, vary for each experiment depending on the external parameters that are fixed. The scales defined in section $2 \mathrm{c}$ for length, wind, and temperature, combined with the nondimensional length $x / D$ and height $z / z_{i}$, are used here to normalize these profiles, thus obtaining the laws that describe the features of the UHI above the canopy and the urbanbreeze circulation as a function of just three governing parameters $\left[D, z_{i}\right.$, and $\left.\left(H_{u}-H_{r}\right)\right]$.

\section{1) SCALING THE DAYTIME UHI}

Figure 7 shows the normalized profiles of the UHI $\left[\mathrm{UHI} /\left(\mathrm{Cte} \theta_{s}\right)\right.$, with a normalization constant $\mathrm{Cte}=22$; 

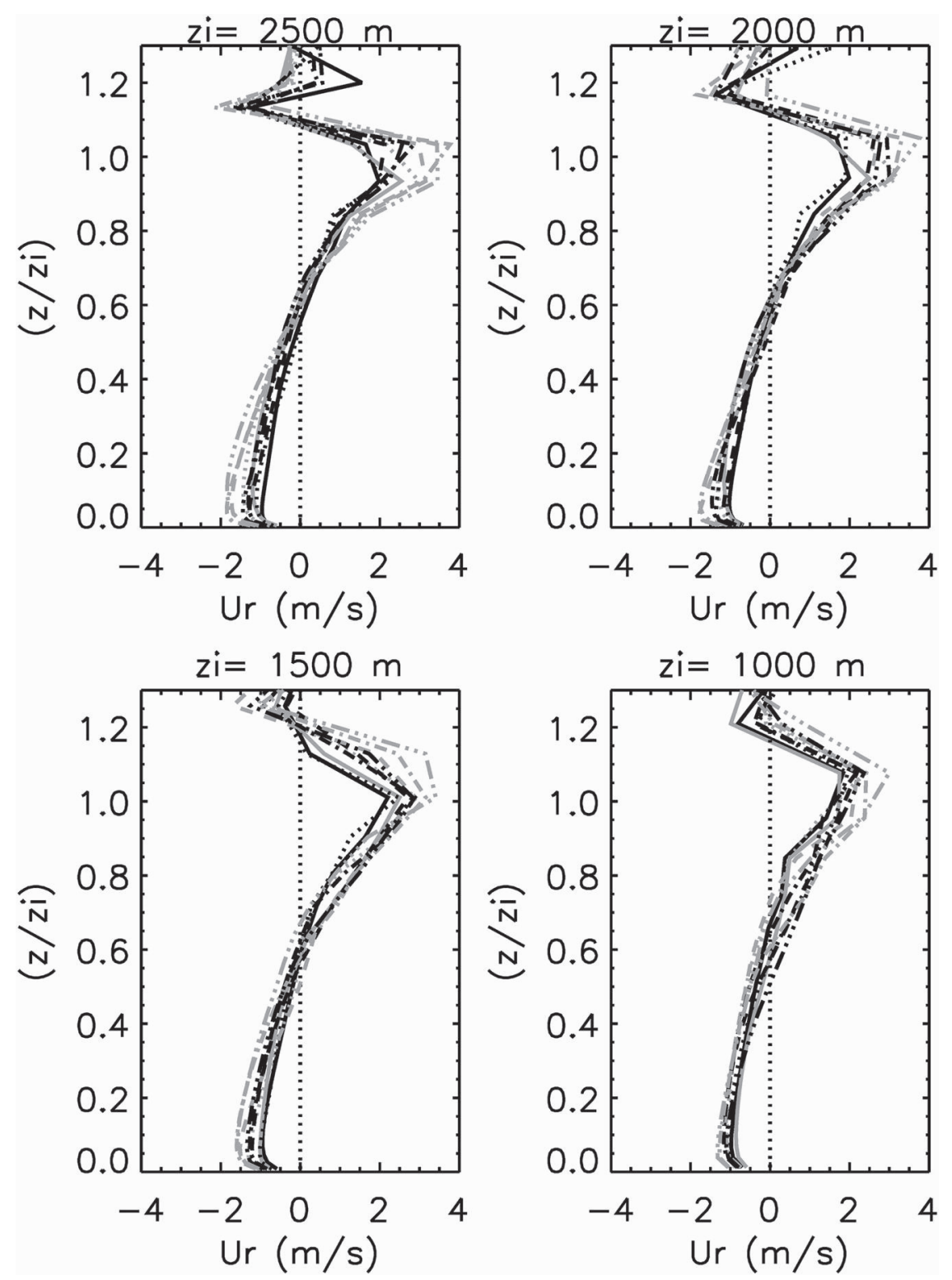

FIG. 5. Vertical profiles of radial velocity as a function of the nondimensional height $z / z_{i}$ for the different simulations. The black lines correspond to the simulation for $D=10 \mathrm{~km}$, and the gray lines correspond to the simulation for $D=20 \mathrm{~km}$.

$\theta_{s}$ is defined by Eq. (3)] at the first atmospheric level for the 40 simulations. The experiments simulate the top hat-type (peak, plateau, and cliff) spatial distribution of the UHI described by Oke (1987). A least squares polynomial fit is used to obtain the optimal polynomial regression describing the UHI through the city (black line in Fig. 7). Two polynomial fits of order 1 were used to describe the UHI profile: one at the city center and suburbs $(0<x / D<0.45)$ :

$$
\frac{\mathrm{UHI}}{21.7 \theta_{s}}=-1.46\left(\frac{x}{D}\right)+1,
$$

and one at the edge of the city $(0.45<x / D<0.55)$ :

$$
\frac{\mathrm{UHI}}{21.7 \theta_{s}}=-3.2\left(\frac{x}{D}\right)+1.77 \text {. }
$$

These equations give the UHI intensity above the canopy at different distances from the center of the city as a function of only three (measurable) governing parameters: the size of the city $D$, the boundary layer height $z_{i}$, and the horizontal gradient of sensible heat flux between the city and its surroundings $\left(H_{u}-H_{r}\right)$. The highest dispersion of normalized profiles occurs at 



FIG. 6. As in Fig. 5, but for vertical velocity.

the city center. The dispersion from the fit function drops below $50 \%$ in the suburban area and decreases to zero when approaching the edge of the city.

\section{2) SCALING THE MAXIMUM AND MINIMUM RADIAL AND VERTICAL VELOCITIES}

The normalized vertical profiles of radial velocity shown in Fig. $8\left[U_{r} /\left(\mathrm{Cte} W_{s}\right)\right.$, with Cte $=0.97 ; W_{s}$ is defined in Eq. (2)] predict the maximum intensity at a height of $z / z_{i}=0.05$ for the convergent branch (from surroundings to the city center) and at $z / z_{i}=1.05$ for the divergent branch (from the city to the surroundings) with an intensity of

$$
\begin{aligned}
& \frac{U_{r}}{0.97 W_{s}}=-0.6 \text { at } z / z_{i}=0.05 \text { and } \\
& \frac{U_{r}}{0.97 W_{s}}=1.5 \text { at } z / z_{i}=1.05 .
\end{aligned}
$$

The change in surface wind direction with altitude, from convergent to divergent, creates a transition layer with a region of weak flow situated at $z / z_{i}=0.6$. The radial velocity reaches zero again at the top of the entrainment zone $\left(z / z_{i}=1.18\right)$ where the urban influence ceases to be perceptible. 


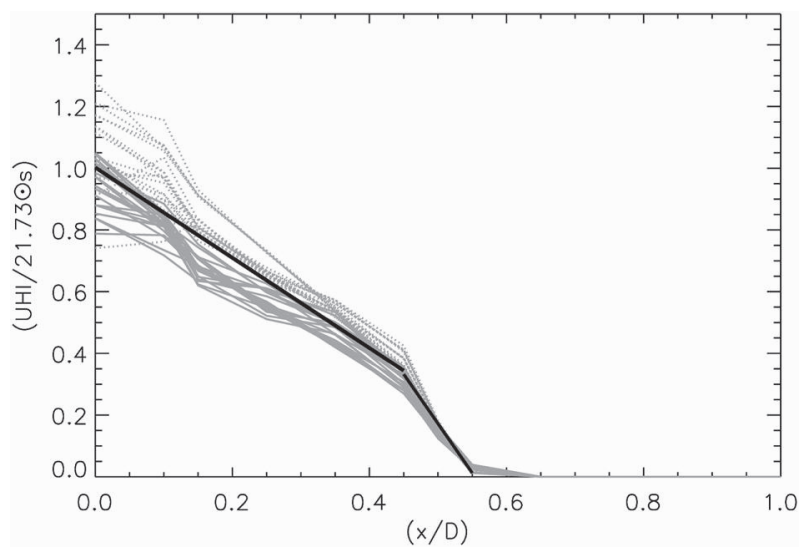

FIG. 7. Normalized horizontal profiles of surface temperature distribution (12-m height) from the center of the domain. The continuous gray lines correspond to the simulation for $D=10 \mathrm{~km}$, the dotted gray lines correspond to the simulation for $D=20 \mathrm{~km}$, and the black lines represent the best least squares polynomial fit. The center of the city is situated at $x / D=0$; the edge of the urban area lies at $x / D=0.5$.

The vertical velocity at the city center increases with height from zero at the surface to a maximum at about one-half of the boundary layer height. The normalized $\left\{W /\left[\mathrm{Cte} W_{s}\left(z_{i} / D\right)\right] ;\right.$ Cte $\left.=4.33\right\}$ vertical profiles are shown in Fig. 9. The maximum vertical velocity has a value of

$$
\frac{W}{4.33 W_{s}\left(z_{i} / D\right)}=1.3 \quad \text { at } z / z_{i}=0.68
$$

The stability at the top of the urban boundary layer prevents this mass of air from rising any further, and the vertical velocity becomes zero at a height of $z / z_{i}=1.18$.

\section{3) SCALING THE VERTICAL PROFILES OF THE URBAN-BREEZE CIRCULATION}

A general equation describing the normalized vertical profiles of radial (at $0.2 \leq x / D \leq 0.4$ ) and vertical velocity (at the city center $D \leq 0.2$ ) fields was obtained, as for the temperature, with a least squares polynomial fit function, as follows. The vertical profile of the radial velocity increases with height following the known logarithmic law due to the roughness length imposed at the surface (section 3). The surface drag starts to be negligible at a height of $z / z_{i}=0.05$. A quadratic polynomial law is used to describe the vertical profile from this height up to $z / z_{i}=1.05$ :

$$
\begin{aligned}
& \frac{U_{r}}{0.97 W_{s}}=2.08\left(\frac{z}{z_{i}}\right)^{2}-0.21\left(\frac{z}{z_{i}}\right)-0.60 \text { for } \\
& 0.05 \leq z / z_{i} \leq 1.05 .
\end{aligned}
$$

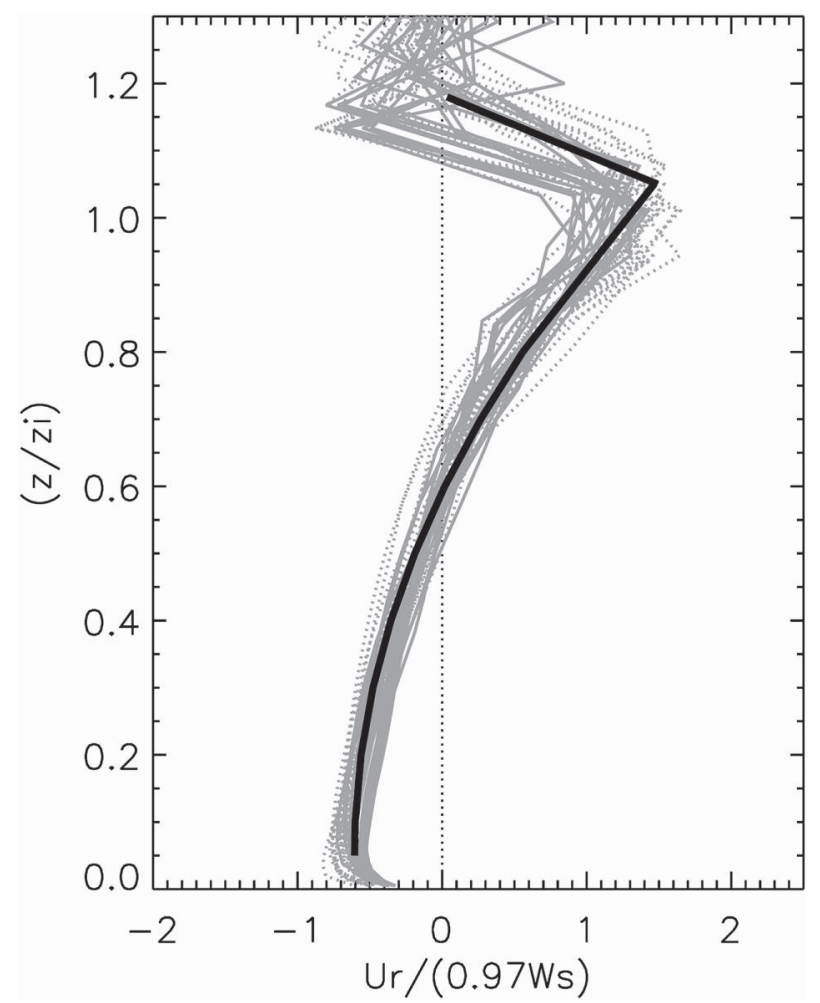

FIG. 8. Normalized profiles of radial velocity $U_{r}$. The continuous gray lines correspond to the simulation for $D=10 \mathrm{~km}$, the dotted gray lines correspond to the simulation for $D=20 \mathrm{~km}$, and the black lines represent the best least squares polynomial fit.

From that point to the top of the boundary layer (top of the entrainment zone), the radial velocity decreases to zero. Only two levels of the model are situated in this thickness, and, for this reason, the deceleration of the horizontal wind is described by a straight line:

$\frac{U_{r}}{0.97 W_{s}}=-11.20\left(\frac{z}{z_{i}}\right)+13.25$ for $1.05 \leq z / z_{i} \leq 1.18$.

A cubic polynomial fit was then used to describe the vertical velocity profile from the surface to the top of the ABL:

$$
\begin{aligned}
\frac{W}{4.33 W_{s}\left(z_{i} / D\right)}= & -2.04\left(\frac{z}{z_{i}}\right)^{3}+0.16\left(\frac{z}{z_{i}}\right)^{2} \\
& +2.63\left(\frac{z}{z_{i}}\right) \text { for } 0 \leq z / z_{i} \leq 1.18
\end{aligned}
$$

For both radial velocity and vertical velocity, the dispersion from the fitted curve was higher at the top of the boundary layer, with better results for vertical velocity at low levels, where it approached zero, and more homogeneous results for radial velocity. 


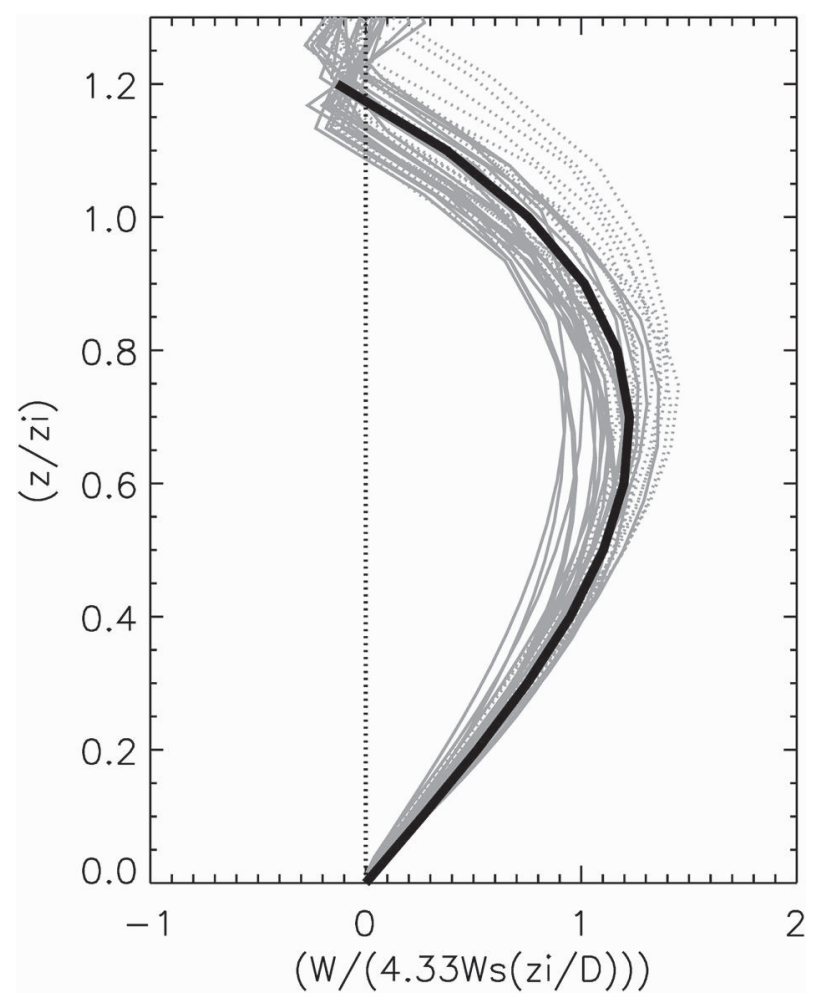

FIG. 9. As in Fig. 8, but for vertical velocity $W$.

The general scaling laws are able to reproduce the urban-breeze case observed in Toulouse (Hidalgo et al. 2008a) [forcing parameters: $z_{i}=2000 \mathrm{~m}, D=10000 \mathrm{~m}$, and $\left.\left(H_{u}-H_{r}\right)=0.165 \mathrm{~m} \mathrm{~K} \mathrm{~s}^{-1}\right]$. In Table 1 are presented the intensity of the UHI over the canopy in the city center and in the suburban zone, the horizontal convergent and divergent branches, and the maximal vertical wind speed.

The scaling laws' predictions for the urban heat island intensity and horizontal wind compare well to those observed and modeled by Hidalgo et al. (2008a,b). The vertical wind speed is overestimated with respect to the speed obtained in the realistic run ("URB"; Hidalgo et al. 2008b). This is due to the absence of mean largescale wind in the simplified model. In the real world, synoptic winds from a dominant direction almost always exist and tend to destroy local circulations by turbulence and diminish the UHI strength.

This study assumed a certain number of simplifications (e.g., nonexistent large-scale mean wind, dry atmosphere, circular city) to obtain a simplified set of equations that gives a realistic daytime circulation intensity generated by a specified city using only three measurable parameters. Despite the limitations of this idealized approach, these relationships can also be used to quantify the impact on the boundary layer thermodynamics when the
TABLE 1. Scaling-law validation. Observational values come from the observed and simulated urban-breeze episode during the IOP5 of the CAPITOUL campaign.

\begin{tabular}{ll}
\hline \hline CAPITOUL IOP5 case & New scaling-law prediction \\
\hline $\mathrm{UHI}_{x=0}=1-1.5 \mathrm{~K}$ & $\mathrm{UHI}_{x=0}=1.5 \mathrm{~K}$ \\
$\mathrm{UHI}_{0.2<x / D<0.4}=0.5 \mathrm{~K}$ & $\mathrm{UHI}_{0.2<x / D<0.4}=0.6 \mathrm{~K}$ \\
$U_{r(z=350 \mathrm{~m})}=1.41 \mathrm{~m} \mathrm{~s}^{-1}$ & $U_{r(z=350 \mathrm{~m})}=1.2 \mathrm{~m} \mathrm{~s}^{-1}$ \\
$U_{r(z=1650 \mathrm{~m})}=1.25 \mathrm{~m} \mathrm{~s}^{-1}$ & $U_{r(z=1650 \mathrm{~m})}=1.4 \mathrm{~m} \mathrm{~s}^{-1}$ \\
$W_{z=1200 \mathrm{~m}}=1-1.5 \mathrm{~m} \mathrm{~s}^{-1}$ & $W_{z=1200 \mathrm{~m}}=2.2 \mathrm{~m} \mathrm{~s}^{-1}$ \\
\hline
\end{tabular}

city size $D$, the meteorological conditions $z_{i}$, and the urban morphology [or human activity, expressed by a fixed value of $\left(H_{u}-H_{r}\right)$ ] change as a result of urban planning and development.

\section{Conclusions}

A new approach for scaling the daytime UHI and urban-breeze characteristics has been developed in this paper. The external forcing that pilots the urban-breeze circulation development and evolution has been identified and used to obtain a set of simple scaling laws describing the urban-breeze features as a function of governing variables. Nocturnal and diurnal differences on the atmospheric boundary layer development have been pointed out, focusing on the importance of the fact that the mixed layer is unstable during daytime and there is no notion of mean stability of the atmosphere (as in the rural nocturnal layer in which the nocturnal UHI forms). The forcing parameters chosen are the size of the city $D$, the height $z_{i}$ of the inversion layer that tops the mixed layer, and the difference (urban - rural) of surface heat flux $\left(H_{u}-H_{r}\right)$.

Three-dimensional high-resolution numerical simulations were the strategy chosen to examine the dependence of physical processes on the external forcing involved in the diurnal urban-breeze circulation. A set of simulations performed with the Meso-NH atmospheric model provided a set of urban-breeze circulations forced by an urban environment.

The ability of the idealized model to reproduce the urban breeze accurately in such an idealized context has been verified by emulating the urban-breeze episode observed in Toulouse during IOP5. The model simulates a surface UHI of $1.5 \mathrm{~K}$ and a horizontal wind speed in the convergent branch of the urban breeze reaching a maximum of $1.2 \mathrm{~m} \mathrm{~s}^{-1}$, which compares well to the observations for the real city. The $2 \mathrm{~m} \mathrm{~s}^{-1}$ vertical wind speed in the upward motion of the urban breeze over the city is slightly larger than that obtained by a realistic simulation of the IOP5 case during the CAPITOUL campaign (1.5 $\mathrm{m} \mathrm{s}^{-1}$; Hidalgo et al. 2008b). 
General laws describing the normalized profiles of temperature and wind fields have been obtained. For example, daytime UHI maximal intensity, maximal radial velocity in convergent and divergent branches, and maximum vertical velocity in the urban-breeze motion scaling laws are

$$
\begin{aligned}
\mathrm{UHI} & =21.7\left(H_{u}-H_{r}\right)^{2 / 3}\left(\beta z_{i}\right)^{-1 / 3}, \\
U_{r} & =-0.6 \times 0.97\left[\beta z_{i}\left(H_{u}-H_{r}\right)\right]^{1 / 3}, \\
U_{r} & =1.5 \times 0.97\left[\beta z_{i}\left(H_{u}-H_{r}\right)\right]^{1 / 3}, \text { and } \\
W & =1.3 \times 4.33\left[\beta\left(H_{u}-H_{r}\right)\right]^{1 / 3} z_{i}^{4 / 3} D^{-1} .
\end{aligned}
$$

The scaling laws obtained should be verified with other datasets from future observations or laboratory experiments. The impact of wind strength on the UHI, and the transition from urban breeze to urban plume as the wind increases, could be also assessed in further research.

The relationships obtained can be used to quantify the impact on the boundary layer thermodynamics, in terms of temperature and wind dynamics, when the city size $D$, the meteorological conditions $z_{i}$, and the urban morphology [expressed as a fixed value $\left(H_{u}-H_{r}\right)$ ] change as a result of urban planning and development. Scaling laws could be used to produce "synthetic" UHI that, combined with the regional climatological data, would take the spatial variability into account at the city scale, which is not currently represented in global and regional climate models.

Acknowledgments. This research was performed at the University of Vigo and the GAME/CNRM (MétéoFrance, CNRS) and was supported with a Ph.D. grant cofunded by both institutions (Education and Science Ministry; DINPRE Project, Ref: CGL2004-05187-C0302/CLI)

\section{REFERENCES}

Atkinson, B. W., 2002: Numerical modelling of urban heat-island intensity. Bound.-Layer Meteor., 109, 285-310.

Baik, J. J., 1992: Response of a stably stratified atmosphere to lowlevel heating-An application to the heat island problem. J. Appl. Meteor., 31, 291-303.

- and H. Chun, 1997: A dynamical model for urban heat islands. Bound.-Layer Meteor., 83, 463-477.

—, Y.-H. Kim, and H.-Y. Chun, 2001: Dry and moist convection forced by an urban heat island. J. Appl. Meteor., 40, 14621475.

Bougeault, P., and P. Lacarrère, 1989: Parameterization of orographyinduced turbulence in a mesobeta-scale model. Mon. Wea. Rev., 117, 1872-1890.

Buckingham, E., 1914: On physically similar systems: Illustrations of the use of dimensional equations. Phys. Rev., 4 (4), 345-376.
Cenedese, A., and P. Monti, 2003: Interaction between an inland urban heat island and a sea-breeze flow: A laboratory study. J. Appl. Meteor., 42, 1569-1583.

Changnon, S. A., Jr., Ed., 1981: METROMEX: A Review and Summary. Meteor. Monogr., No. 40, Amer. Meteor. Soc., 181 pp.

Cuxart, J., P. Bougeault, and J.-L. Redelsperger, 2000: A turbulence scheme allowing for mesoscale and large-eddy simulations. Quart. J. Roy. Meteor. Soc., 126, 1-30.

Deardorff, J. W., 1970: Convective velocity and temperature scales for the unstable planetary boundary layer and for Rayleigh convection. J. Atmos. Sci., 27, 1211-1213.

Hidalgo, J., G. Pigeon, and V. Masson, 2008a: Urban-breeze circulation during the CAPITOUL experiment: Experimental data analysis approach. Meteor. Atmos. Phys., 102, 223-241.

_ - V. Masson, and G. Pigeon, 2008b: Urban-breeze circulation during the CAPITOUL experiment: Numerical approach. Meteor. Atmos. Phys., 102, 243-262.

Holtslag, A. A. M., and F. T. Nieuwstadt, 1986: Scaling the atmospheric boundary layer. Bound.-Layer Meteor., 36, 201-209.

Kurbatskii, A., 2001: Computational modeling of the turbulent penetrative convection above the urban heat island in a stably stratified environment. J. Appl. Meteor., 40, 1748-1761.

Lafore, J. P., and Coauthors, 1998: The Meso-NH Atmospheric Simulation System. Part I: Adiabatic formulation and control simulation. Ann. Geophys., 16, 90-109.

Lemonsu, A., and V. Masson, 2002: Simulation of a summer urban breeze over Paris. Bound.-Layer Meteor., 104, 463-490.

Lin, Y., 1987: Two-dimensional response of a stably stratified shear flow to diabatic heating. J. Atmos. Sci., 44, 1375-1393.

_ , and R. B. Smith, 1986: Transient dynamics of airflow near a local heat source. J. Atmos. Sci., 43, 40-50.

Lu, J., S. P. Arya, W. H. Snyder, and R. E. Lawson, 1997a: A laboratory study of the urban heat island in a calm and stably stratified environment. Part I: Temperature field. J. Appl. Meteor., 36, 1377-1391.

,,$-- \ldots$, and $\_$1997b: A laboratory study of the urban heat island in a calm and stably stratified environment. Part II: Velocity field. J. Appl. Meteor., 36, 1392-1402.

Masson, V., 2000: A physically-based scheme for the urban energy budget in atmospherics models. Bound.-Layer Meteor., 94, 357-397.

— , and Coauthors, 2008: The Canopy and Aerosol Particles Interactions in TOulouse Urban Layer (CAPITOUL) experiment. Meteor. Atmos. Phys., 102, 135-157.

Oke, T. R., 1982: The energetic basis of the urban heat island. Quart. J. Roy. Meteor. Soc., 108, 1-24.

_ 1987: Boundary Layer Climates. Methuen, 435 pp.

Olfe, D. B., and R. L. Lee, 1971: Linearized calculations of urban heat island convection effects. J. Atmos. Sci., 28, 1374 1388.

Porson, A., D. G. Steyn, and G. Schayes, 2007: Sea-breeze scaling from numerical model simulations, Part I: Pure sea breezes. Bound.-Layer Meteor., 29, 17-29.

Richardone, R., and G. Brusasca, 1989: Numerical experiments on urban heat island intensity. Quart. J. Roy. Meteor. Soc., 115, 983-995.

Shea, D. M., and A. H. Auer Jr., 1978: Thermodynamic properties and aeorosol patterns in the plume downwind of St. Louis. J. Appl. Meteor., 17, 689-698.

Shreffler, J. H., 1978: Detection of centripetal heat-island circulation from tower data in St. Louis. Bound.-Layer Meteor., 15, 229-242. 
_ 1979: Heat island convergence in St. Louis during calm periods. J. Appl. Meteor., 18, 1512-1520.

Steyn, D., 1998: Scaling the vertical structure of sea breeze. Bound.-Layer Meteor., 86, 505-524.

Stull, R., 1997: An Introduction to Boundary Layer Meteorology. Kluwer Academic, 442 pp.

Vaschy, A., 1892: Sur les lois de similitude en physique (On the laws of similarity in physics). Ann. Télégr., 19, 25-28.
Vukovich, F. M., and J. W. Dunn, 1978: A theoretical study of the St. Louis heat island: Some parameter variations. J. Appl. Meteor., 17, 1585-1594.

Wong, K. K., and R. A. Dirks, 1978: Mesoscale perturbations on airflow in the urban mixing layer. J. Appl. Meteor., 17, 677-688.

Yoshikado, H., 1992: Numerical study of the daytime urban effect and its interaction with the sea breeze. J. Appl. Meteor., 31, 1146-1164. 